\title{
Diffuse ST segment depression from hypothermia
}

\author{
Hao Wang • Joseph Hollingsworth • Simon Mahler • \\ Thomas Arnold
}

Received: 30 March 2010 /Accepted: 21 June 2010 /Published online: 21 August 2010

(C) Springer-Verlag London Ltd 2010

\begin{abstract}
Hypothermia is known to cause specific electrocardiographic (EKG) changes such as Osborne waves and bradycardia. We report diffuse ST segment depression, an atypical EKG change, in a patient with a core temperature of $29.4^{\circ} \mathrm{C}\left(85^{\circ} \mathrm{F}\right)$. This patient had no previous cardiovascular pathology, and his EKG changes resolved gradually with aggressive warming. We also discuss the pathophysiology and clinical significance of ST depression in the general population and the typical EKG changes in hypothermia patients.
\end{abstract}

Keywords Electrocardiography $\cdot$ Hypothermia .

ST depression

\section{Case report}

A 46-year-old African American male was brought to the Emergency Department (ED) by helicopter at 3:00 a.m. on a cold January morning. It was reported that the patient had an altered level of consciousness and was found lying in the middle of a street in wet clothes. He was also noted to have a strong smell of alcohol. The patient could open his eyes spontaneously, move all extremities and follow commands. However, he had a Glasgow Coma Scale score of 13

H. Wang $(\triangle) \cdot J$. Hollingsworth $\cdot$ S. Mahler $\cdot$ T. Arnold Department of Emergency Medicine, Louisiana State University Health Science Center at Shreveport,

Shreveport, LA 71130, USA

e-mail: hwang01@jpshealth.org

Present Address:

H. Wang

Department of Emergency Medicine, JPS Health Network, Fort Worth, TX 76104, USA initially because he was disoriented and using inappropriate words.

On physical examination, he appeared to be a welldeveloped, well-nourished African-American male. He was somnolent, but was easily arousable. His vital signs included a heart rate of $70 \mathrm{bpm}$ (sinus rhythm), a respiratory rate of $12 / \mathrm{min}$, a blood pressure of $115 /$ $71 \mathrm{mmHg}$, and a pulse oximetry of $96 \%$ on 21 of oxygen via nasal cannula. His skin was wet and cold to the touch. Following removal of his wet clothes, his core temperature was found to be $29.4^{\circ} \mathrm{C}\left(85^{\circ} \mathrm{F}\right)$ via a rectal probe. This patient was found to have swelling on his left maxilla with a superficial laceration and no active bleeding. There were no other external signs of trauma. The patient had no focal neurological deficits. Otherwise, his physical examination was unremarkable.

The patient was aggressively rewarmed. Warm blankets including a warm air blanket (Bair Hugger) were applied to the patient. In addition, warm normal saline (NS) was administered intravenously, and a Foley catheter was placed for warm NS irrigation. A rectal temperature probe was placed for continuous core temperature monitoring.

On presentation, an EKG was obtained (see Fig. 1) showing significant ST segment depression in leads II, III, aVF and V3-6. Laboratory tests were obtained, revealing a high blood alcohol level, a mild elevation of WBC $(11.42 \mathrm{~K} / \mu \mathrm{l})$, high anion gap $(19 \mathrm{mmol} / \mathrm{l})$, low bicarbonate (14 mmol/l), and mildly elevated CPK (3,010 U/l). Otherwise, laboratory results were unremarkable, including two normal troponin I values (first $0.03 \mathrm{ng} / \mathrm{ml}$ and $0.04 \mathrm{ng} /$ $\mathrm{ml} 2 \mathrm{~h}$ after) and negative urine drug screen test. The patient had computed tomography of his head, which was negative for fracture or intracranial abnormalities.

After aggressive external warming, the patient's core temperature reached $33.9^{\circ} \mathrm{C}\left(93^{\circ} \mathrm{F}\right)$ and an $\mathrm{EKG}$ was 


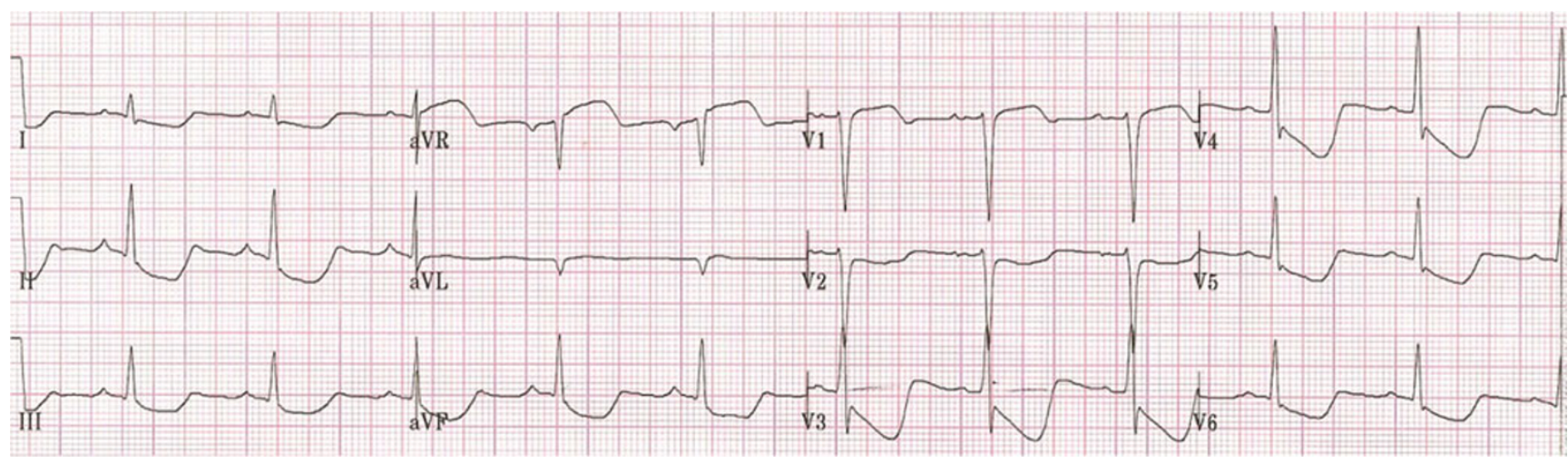

Fig. 1 Diffuse significant ST segment depression in leads II, III, aVF and V3-6 in a patient with core body temperature of $85^{\circ} \mathrm{F}$

repeated (Fig. 2). This EKG demonstrated a normal sinus rhythm with no ST depression. The patient was stabilized in the ED and admitted to the hospital for further evaluation and treatment.

\section{Discussion}

Hypothermia affects almost all organ systems, especially the cardiovascular with different EKG changes. Sinus bradycardia, junctional bradycardia, atrial fibrillation, QT prolongation, PR prolongation, widening of the QRS complex and Osborne waves ( $\mathrm{J}$ waves) are the most common EKG changes. Most EKG changes develop when moderate or severe hypothermia occurs. Moderate hypothermia is usually considered when core body temperature drops to $32^{\circ} \mathrm{C}\left(90^{\circ} \mathrm{F}\right)$, and severe hypothermia is defined as body core temperature below $28^{\circ} \mathrm{C}\left(82^{\circ} \mathrm{F}\right)$. Sinus or junctional bradycardia can occur with mild hypothermia. However, it develops most commonly in moderate or severe hypothermia when pacemaker cells decrease depolarization spontaneously. Heart rate can drop over $40 \%$ from its baseline when body temperature becomes moderately hypothermic and drop over 55\% if it reaches severe hypothermia in animal study [1]. Similar findings were also reported in human beings as well [2].

Pathophysiologically, hypothermia depresses the calcium-dependent ATPase (Ca-ATPase) activity by reducing the number of active calcium pump units [3]. The depression of calcium uptake activity delays the inward calcium current, thus prolonging the action potential duration resulting in myocardial conduction delay. The widening QRS complex is developed thereafter. Conduction delay can also cause PR prolongation and high-degree $\mathrm{A}-\mathrm{V}$ blockage in EKG. Increased calcium concentration extracellularly and decreased calcium concentration intracellularly among myocardial cells impairs the cardiac contractility and subsequently reduces the cardiac output [4]. The $\mathrm{Na}+/ \mathrm{H}+$ exchange function was also affected by hypothermia, with delayed activation of the inward sodium current and more $\mathrm{H}+$ retained intracellularly $[5,6]$. The increasing acidosis in the cytosol further affects the enzyme activity, which forms a vicious cycle in the metabolism of myocytes during hypothermia [7].

The mechanisms of atrial fibrillation (A-fib) triggered by hypothermia are still not fully understood and probably multifactorial. Under the circumstance of hypothermia, the sympathetic nervous system is activated with the release of

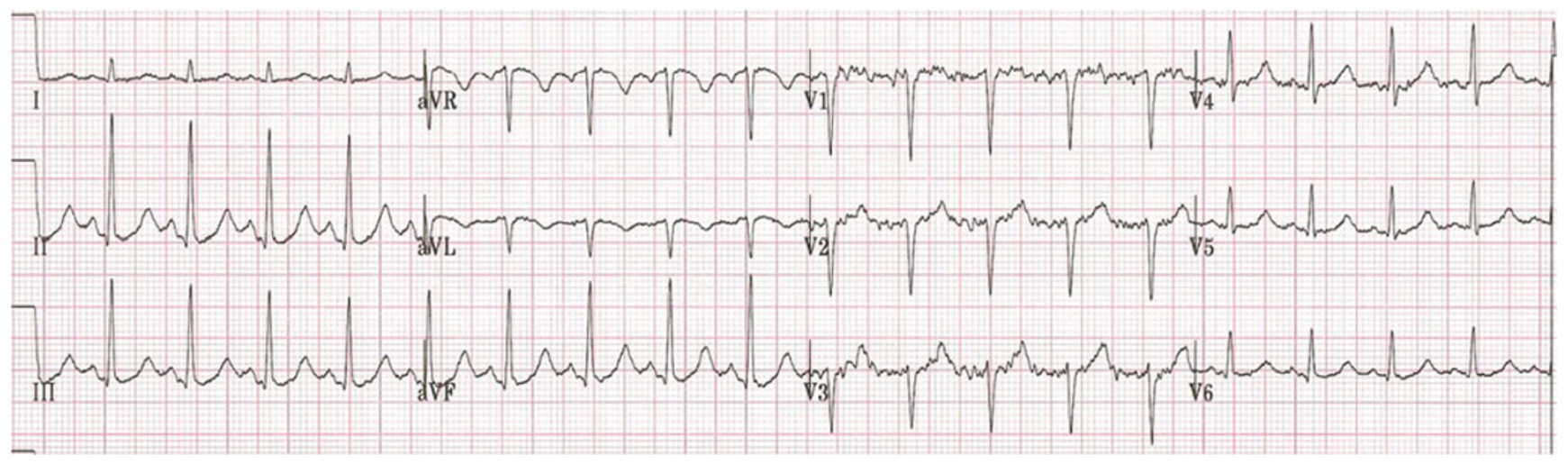

Fig. 2 Sinus tachycardia with no ST segment depression in the same patient with core body temperature of $93^{\circ} \mathrm{F}$ after $2 \mathrm{~h}$ of external warming 
catecholamine. Increased sympathetic innervations trigger the initiation of atrial ectopic activity, which can further progress into A-fib. In addition, acidosis in hypothermia also lowers the threshold of A-fib among these atrial myocytes. A-fib occurs more often when core body temperature drops below $32^{\circ} \mathrm{C}\left(90^{\circ} \mathrm{F}\right)$. If severe hypothermia develops, ventricular fibrillation or asystole can occur.

The QT interval is measured from the time when ventricular myocytes depolarize to the time when they repolarize. Pathophysiologically, hypothermia depresses the pacemaker cells automaticity, affecting the transmembrane ion channel activity, resulting in lower calcium, higher potassium and higher hydrogen levels intracellularly. A shift of these ions from extracellular to intracellular enables hypokalemia to occur more easily around myocytes, which further suppresses the resting membrane potential and induces the QT prolongation [8]. It is reported that over $70 \%$ of hypothermia patients develop QT prolongation [9]. A good linear correlation between the core temperature and the duration of QT interval is seen in animal studies; however, it shows significant variability in human beings $[10,11]$.

Osborne waves are detected in $80 \%$ of patients with a core body temperature below $30^{\circ} \mathrm{C}\left(86^{\circ} \mathrm{F}\right)$, usually occurring in the precordial leads $[12,13]$. The appearance of Osborn waves on EKG was considered to be due to the abnormalities during early ventricular repolarization, and this may be related to the altered transmural action potential [14]. However, the mechanisms are still not fully understood. Osborne waves can be seen in subarachnoid hemorrhage, myocardial ischemia or sepsis patients, and therefore may not be pathognomonic for hypothermia [15-18].

ST segment elevation can be seen in hypothermia patients often with the appearance of Osborne waves because it is partially buried in the $\mathrm{R}$ wave with downsloping ST elevation. If it occurs in leads V1 and V2, ST elevation with Osborn waves can resemble the Brugada syndrome $[19,20]$. One of the mechanisms of the ST change can be attributed to early repolarization and acidosis. Whether the early repolarization is considered benign or malignant also depends on the lead location. If the early repolarization pattern displays only in the lateral precordial leads, it is usually benign. However, if it displays in the inferior, lateral and right precordial leads, this can often develop into malignant arrhythmias and ventricular fibrillation [21].

ST depression occurs significantly less when compared with ST elevation in hypothermia patients. In one prospective, multicenter observational study, ST depression was reported in $17.8 \%(13 / 73)$ of patients with hypothermia. Unfortunately, this study does not report the amplitude of ST depression, the number of leads involved and the relationship to the severity of hypothermia [22]. One case report was published and reported ST depression only from lead V3 to V6 with the appearance of an Osborn wave occurring in an 80-year-old woman with a core body temperature of less than $30^{\circ} \mathrm{C}\left(86^{\circ} \mathrm{F}\right)$, and ST depression was recovered after rewarming [23]. However, until now, the mechanism(s) of ST depression in hypothermia is still uncertain. ST segment depression is not always pathologic. It can be seen in normal patients including those with $\mathrm{AV}$ reciprocating tachycardia, atrial repolarization and hyperventilation, and can be caused by artifacts [24-26]. In patients at high risk of coronary artery disease, ST segment depression often indicates myocardial ischemia. Subendocardial ischemia can manifest as horizontal or down-sloping ST segment depression [27, 28]. Other causes of ST depression include a digoxin effect, hypokalemia, obstructive sleep apnea syndrome, hypertension, CNS diseases, rheumatoid arthritis, mitral valve prolapse and intraventricular conduction abnormalities [29-36].

Here we report a previously healthy young male who developed diffuse ST depression when his core body temperature dropped to $29.4^{\circ} \mathrm{C}\left(85^{\circ} \mathrm{F}\right)$. This patient had significant ST segment depression of more than $1 \mathrm{~mm}$ $(0.1 \mathrm{mV})$ at the $\mathrm{J}$ point on leads II, III, aVF and V3-6 (Fig. 1) with no Osborne waves. The ST segment depression presented as a downward slope towards the end of the ST segment at its junction with the T wave. This patient had no past medical history and was not on any medications that could have accounted for these EKG changes. Coronary artery disease is a very unlikely cause of this patient's EKG changes, given his age and lack of cardiovascular risk factors. Furthermore, during his ED stay, his cardiac enzymes were negative, and his ST segment changes resolved with rewarming. His repeat EKG after body temperature reached $33.9^{\circ} \mathrm{C}\left(93^{\circ} \mathrm{F}\right)$ and showed sinus tachycardia with no ST depression in all 12 leads (Fig. 2). This patient was observed in the hospital overnight and discharged the next day with no observed short-term complications.

In conclusion, in this case report, ST depression can be the only EKG change in hypothermia that can display globally in the inferior and lateral precordial leads. Fortunately, this EKG change in hypothermia seems to be associated with a good outcome after rewarming.

Conflicts of interest None.

\section{References}

1. Dm M, Horton JW (1990) Effect of different degrees of hypothermia on myocardium in treatment of hemorrhagic shock. J Surg Res 48(1):61-67 
2. Maaravi Y, Weiss AT (1990) The effect of prolonged hypothermia on cardiac function in a young patient with accidental hypothermia. Chest 98(4):1019-1020

3. Fukumoto K, Takenaka H, Koga Y, Hamada M (1990) Effect of prolonged hypothermia ischemia on myocardial sarcoplasmic reticular calcium transport. Cardiovasc Res 24(3):169-175

4. Schiffmann H, Gleiss J, von Hirscheydt A, Schroder T, Kahles H, Hellige G (2001) Effects of epinephrine on the myocardial performance and hemodynamics of the isolated rat heart during moderate hypothermia-importance of calcium homeostasis. Resuscitation 50(3):309-317

5. Myers ML, Karmazyn M (1996) Improved cardiac function after prolonged hypothermia ischemia with the $\mathrm{Na}+/ \mathrm{H}+$ exchange inhibitor HOE 694. Ann Thorac Surg 61(5):1400-1406

6. Kiyosue T, Arita M, Muramatsu H, Spindler AJ, Noble D (1993) Ionic mechanisms of action potential prolongation at low temperature in guinea pig ventricular myocytes. J Physiol 468:85-106

7. Fan Z, Makjelski JC (1993) Intracellular $\mathrm{H}+$ and $\mathrm{Ca} 2+$ modulation of trypsin modified ATP sensitive $\mathrm{K}+$ channels in rabbit ventricular myocytes. Circ Res 72(3):715-722

8. Slovis C, Jenkins R (2002) ABC of clinical electrocardiography: conditions not primarily affecting the heart. BMJ 324 (7349):1320-1323

9. de Souza D, Riera AR, Bombig MT, Francisco YA, Brollo L, Filho BL, Dubner S, Schapachnik E, Povoa R (2007) Electrocardiographic changes by accidental hypothermia in an urban and a tropical region. J Electrocardiol 40(1):47-52

10. van der Linde HJ, Deuren BV, Teisman A, Towart R, Gallacher DJ (2008) The effect of changes in core body temperature on the QT interval in beagle dogs: a previously ignored phenomenon, with a method for correction. Br J Pharmacol 154(7):1474-1481

11. Horan M, Edwards AD, Firmin RK, Ablett T, Rawson H, Field D (2007) The effect of temperature on the QTc interval in the newborn infant receiving extracorporeal membrane oxygenation (ECMO). Early Hum Dev 83(4):217-223

12. Nolan J, Soar J (2005) Images in resuscitation: the ECG in hypothermia. Resuscitation 64(2):133-134

13. Osborn JJ (1953) Experimental hypothermia: respiratory and blood PH changes in relation to cardiac function. Am J Physiol 175(3):389-398

14. Yan GX, Antzelevitch C (1996) Cellular basis for the electrocardiographic J wave. Circulation 93(2):372-379

15. Aslan S, Erdem AF, Uzkeser M, Cakir Z, Cakir M, Akoz A (2007) The Osborn wave in accidental hypothermia. J Emerg Med 32(3):271

16. Salerno D, Vahid B, Marik PE (2007) Osborn wave in hypothermia from Vibrio vunificus sepsis unrelated to exposure. Int J Cardiol 114(3):e124-e125

17. Kalla H, Yan GX, Marinchak R (2000) Ventricular fibrillation in a patient with prominent $\mathrm{J}$ (Osborn) waves and ST segment elevation in the inferior electrocardiographic leads: a Brugada syndrome variant? J Cardiovasc Electrophysiol 11(1):95-98

18. Yan GX, Lankipalli RS, Burke JF, Musco S, Kowey PR (2003) Ventricular repolarization components on the electrocardiogram: cellular basis and clinical significance. J Am Coll Cardiol 42 (3):401-409

19. Ortega-Carnicer J, Benezet J, Caldron-Jimernez P, Yanes-Martin J (2008) Hypothermia induced Brugada like electrocardiogram pattern. J Electrocardiol 41(6):690-692
20. Noda T, Shimizu W, Tanaka K, Chayama K (2003) Prominent J wave and ST segment elevation: serial electrocardiographic changes in accidental hypothermia. J Cardiovasc Electrophysiol 14(2):223

21. Antzelevitch C, Yan GX (2010) J wave syndromes. Heart Rhythm 7(4):549-558

22. Graham CA, McNaughton GW, Wyatt JP (2001) The electrocardiogram in hypothermia. Wild Environ Med 12(4):232-235

23. Benezet-Mazuecos J, Ibanez B, Farre J (2006) Severe hypothermia showing Osborn waves associated with transient atrial fibrillation and ST segment depression. Heart 92(11):1666

24. Riva SI, Della Bella P, Fassini G, Carbucicchio C, Tondo C (1996) Value of analysis of ST segment changes during tachycardia in determining type of narrow QRS complex tachycardia. J Am Coll Cardiol 27(6):1480-1485

25. Agarwal P, Arora SR, Agarwal S, Aneja GK, Agarwal PK (1998) Exercise ECG testing using different protocols in asymptomatic healthy young subjects. Indian J Physiol Pharmacol 42(2):303-306

26. Hughes K (1997) Prevalence rates of major and minor electrocardiogram abnormalities in the Singapore general population. Ann Acad Med Singapore 26(2):161-164

27. Ogawa H, Hiramori K, Haze K, Saito M, Sumiyoshi T, Fukami K, Goto Y, Ikeda M (1985) Classification of non-Q-wave myocardial infarction according to electrocardiographic changes. Br Heart J 54(5):473-478

28. Pulido JI, Parkey RW, Lewis SE, Buja LM, Bonte FJ, Dehmer G, Stone MJ, Willerson JT (1980) Acute subendocardial myocardial infarction: its detection by Tc-99 $\mathrm{m}$ stannous pyrophosphate myocardial scintigraphy. Clin Nucl Med 5(5):191-195

29. Safadi R, Levy I, Amitai Y, Caraco Y (1995) Beneficial effect of digoxin-specific $\mathrm{Fab}$ antibody fragments in oleander intoxication. Arch Intern Med 155(19):2121-2125

30. Winterborn C, Cousins J, Doyle P (2005) Hypokalaemia induced ST segment depression. Anaesthesia 60(10):1044

31. Alonso-Fernández A, García-Río F, Racionero MA, Pino JM, Ortuño F, Martínez I, Villamor J (2005) Cardiac rhythm disturbances and ST-segment depression episodes in patients with obstructive sleep apnea-hypopnea syndrome and its mechanisms. Chest 127(1):15-22

32. Uen S, Baulmann J, Düsing R, Glänzer K, Vetter H, Mengden $\mathrm{T}$ (2003) ST-segment depression in hypertensive patients is linked to elevations in blood pressure, pulse pressure and double product by 24-h Cardiotens monitoring. J Hypertens 21 (5):977-983

33. Sakr YL, Lim N, Amaral AC, Ghosn I, Carvalho FB, Renard M, Vincent JL (2004) Relation of ECG changes to neurological outcome in patients with aneurysmal subarachnoid hemorrhage. Int J Cardiol 96(3):369-373

34. Lindgren A, Wohlfart B, Pahlm O, Johansson BB (1994) Electrocardiographic changes in stroke patients without primary heart disease. Clin Physiol 14(2):223-231

35. Wisłowska M, Sypuła S, Kowalik I (1999) Echocardiographic findings and 24-h electrocardiographic Holter monitoring in patients with nodular and non-nodular rheumatoid arthritis. Rheumatol Int 18(2):163-169

36. Roger RL, Mitarai M, Mattu A (2006) Intraventricular conduction abnormalities. Emerg Med Clin N Am 24:41-51 